Please quote as: Hirdes, E. M. \& Leimeister, J. M. (2013): A Modeling Language to Describe Reusable Learning Processes to Achieve Educational Objectives in Serious Games. In: 8th European Conference on Technology Enhanced Learning (EC-TEL), Paphos, Cyprus 


\title{
A Modeling Language to Describe Reusable Learning Processes to Achieve Educational Objectives in Serious Games
}

\author{
Eike M. Hirdes, Jan Marco Leimeister \\ Kassel University, Information Systems, Kassel, Germany \\ \{hirdes, leimeister\}@uni-kassel.de
}

\begin{abstract}
Serious games combine motivational aspects of games with pedagogical approaches to enhance their players' learning performance. A major challenge in serious game development is the proper alignment of concepts coming from the two domains, game development and pedagogy. As a consequence, creating successful serious games is difficult for single individuals only well versed in one domain, but not knowing about the other. Existing approaches focus on formalizing learning processes within individual games, but are incapable of making the instructor's knowledge reusable in other serious games. To address this issue, we present a modeling language to capture pedagogical knowledge in reusable learning processes that enable game developers to create serious games that support imparting educational objectives. As a result, our language helps game developers to integrate educational approaches into serious games. The paper illustrates the model and structure of the language.
\end{abstract}

Keywords: serious games, modeling language, game development, educational objectives

\section{Motivation}

Games can increase the effectiveness of learning processes [1]. Educational objectives are integrated within games, so that users can reach these playfully, while the nature of the game incites and motivates users [2]. These are so-called serious games (SG), digital games which engage the user and instruct him.

To enhance the players' learning performance and simultaneously achieve learning outcomes (educational objectives), pedagogical methods and approaches need to be integrated into the digital game's story [3]. During the development process of a SG the toughest challenge is the alignment of pedagogy and the game itself [4]. Two domains need to be taken into account, game development, which deals with motivation of the user, and pedagogy, which aims to achieve learning outcomes. As a consequence, creating successful SGs is difficult for single individuals only well versed in one domain, but not knowing about the other. But the transition of educational methods and techniques into SGs has not been done in a structured and standardized way [5]. The aim of our work is to facilitate and stimulate the transition of pedagogy to 
SGs. SGs developers should be able to rely on formalized learning processes for SGs based on activities linked to educational theories and models. Furthermore, these processes should not describe the actual 'run' of a learning process. Thus, they should be reusable without having specific learning and game content, which will be added when deploying these processes during development.

For this purpose a modeling language is required to create a standardized description of learning processes to achieve educational objectives within SGs. Our work aims to answer the following research questions: What are the requirements for a modeling language to describe reusable learning processes to achieve educational objectives in SGs? What are the structure and elements of the prior mentioned modeling language?

The structure of this paper is as follows: Section 2 presents the requirements for the modeling language, the structure and elements of which will be presented in section 3 . Finally, section 4 presents conclusions, limitations and future work.

\section{Requirements to describe Learning Processes in SGs}

The modeling language to describe reusable learning processes to achieve educational objectives in SGs should take into account the requirements (RQ) described in this section. The requirements where derived upon reasoning and the study of literature. Firstly, we describe General Requirements.

- RQ1 Completeness: The modeling language must be able to completely describe a learning process to achieve an educational objective, including all activities and the relationships between those. [6]

- RQ2 Abstraction: The modeling language must be able to describe learning processes as generalizations to achieve educational objectives. Thus, they should be free from specific learning and game content. The processes can be instantiated and adapted to the developers needs during SG development process. [6]

- RQ3 Precondition: Preconditions for a learning process should be specified to describe necessary characteristics of a SG, which need to be fulfilled to successfully deploy the learning process (e.g. single / multiplayer capability). [7]

- RQ4 Reproducibility: The modeling language should describe learning processes that repeated application in different game development processes is possible. [6]

Requirements for the Structure of Learning Processes define the structure and guidelines for the composition of learning processes consisting of activities:

- RQ5 Modular composition: Learning processes to reach educational objectives must be constructed from activities. [7]

- RQ6 Sequencing: The order in which the activities of a learning process have to be performed needs to be specified. This order ensures that all activities of an educational model implemented within a SG are followed in the correct sequence to achieve learning outcomes. [7]

- RQ7 Selection: Activities within a learning process should be able to be specified as optional. During instantiation of the learning process, these blocks can be omitted by game developers to better adapt the learning process to a SG. [7] 
- RQ8 Reusability: All activities of a learning process should be extracted and reused in other learning processes. [8]

- RQ9 Recurring patterns: Activities within a learning process could be bundled and named. This should reduce complexity and allow the reuse of frequently needed sequences of activities. [5, 9]

Requirements to Support Learning are characteristics to illustrate learning in SGs:

- RQ10 Educational objective: The learning outcome must be specified as an educational objective. This supports the focused composition of activities on a target and a measurement for the efficiency and effectiveness of a learning process. [5, 7]

- RQ11 Pedagogical flexibility: It must be able to describe learning processes that are based on different educational models. These models could include, among others, problem-based learning, anchored instruction, cognitive apprenticeships, reciprocal teaching, goal-based scenarios and project-based learning. [5, 6, 10]

- RQ12 Presentation: To reach educational objectives, the learner should be provided with learning stimulations and learning content. Learning processes should allow presentation of these to the user. [11, 12]

- RQ13 Assessment: Learning processes should provide a way to evaluate the learning progress of the user. Thus, assessments needs to be implemented which can be used to reflect the current progress (RQ14) or adapt the learning process to the user's needs (RQ15). [9, 12]

- RQ14 Feedback: Learning processes for SGs should provide feedback to inform the learner about learning / game progress. It can be given immediately on events in the game or actions taken by the user or delayed and summative. [9, 12, 13]

- RQ15 Adaptation: The learning process must be able to describe personalization and adaptation aspects, so that the succeeding activities within the process can be adapted based on the preferences of the user or upon assessment results. [6, 9]

- RQ16 Roles: Activities in learning process should allow different roles, especially learner and instructor. In this way, certain activities of the learning process can only be fulfilled by certain roles (i.e. evaluation of a written assessment can only be done by an instructor). [6]

Requirements to Support Engagement are used to describe user involvement, engagement and playfulness in learning processes:

- RQ17 Non-linearity: A learning process should allow non-linearity. Based on the non-linear structure of games, a learner should be able to follow two or more parallel active tasks or activities. [14]

- RQ18 Rewards: When completing a learning process partially or wholly a learner should be able to receive a reward, i.e. points or achievements. [13]

\section{$3 \quad$ A Modeling Language to Describe Reusable Learning Processes in SGs}

The raised requirements serve as a basis to describe elements and develop a model of a modeling language to describe reusable learning processes for SGs. According to our prior work, we are using the terms serious game pattern (SGP), serious game 
bricks (SGB) and serious game composites (SGC) for our modeling language [5]. SGBs are activities, which can be sequenced to model the flow within a SG (RQ5). Activities can be bundled for reuse and these bundles are called SGC (RQ9). SGCs can consist of two or more SGBs and SGCs. Finally, SGPs are specialized SGCs also consisting of SGBs and SGCs. But contrary to SGCs, SGPs are associated with an educational objective and an educational model (RQ10, 11). These SGPs represent learning processes and are free from actual learning and game content [5] (RQ2, 4). Fig. 1 represents a model of the modeling language we propose.

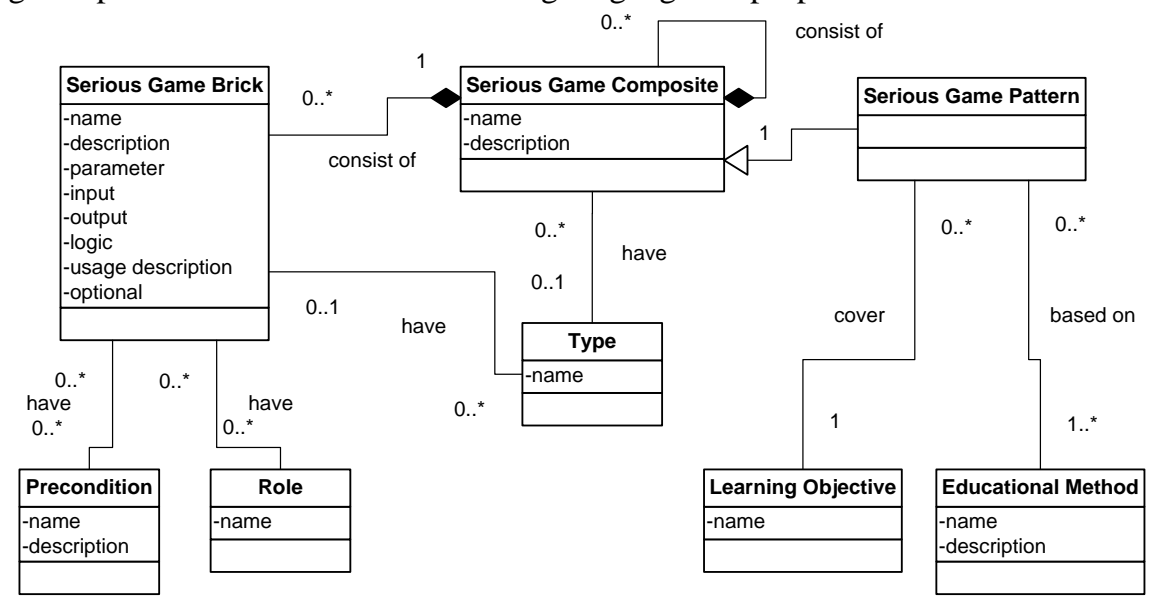

Fig. 1. Serious game learning process model

Table 1 offers a description to each class of our learning process model, their relation to each other, their associated attributes, as well as the requirements they are based on.

Table 1. Classes and attributes of the serious game learning process model

\begin{tabular}{|l|l|}
\hline Class / attribute & Description \\
\hline $\begin{array}{l}\text { Serious Game } \\
\text { Pattern (SGP) }\end{array}$ & $\begin{array}{l}\text { SGPs describe learning processes and consolidate the actions a learner } \\
\text { has to perform to attain learning objectives. (RQ1, 6) }\end{array}$ \\
\hline $\begin{array}{l}\text { Learning Objec- } \\
\text { tive }\end{array}$ & $\begin{array}{l}\text { The learning objective describes the intended outcome of the learning } \\
\text { process based on Bloom's revised cognitive domain [15] (RQ10) }\end{array}$ \\
\hline $\begin{array}{l}\text { Educational } \\
\text { Method }\end{array}$ & $\begin{array}{l}\text { Provides the educational method the learning process is based on. } \\
\text { (RQ11) }\end{array}$ \\
\hline $\begin{array}{l}\text { Serious Game } \\
\text { Brick (SGB) }\end{array}$ & $\begin{array}{l}\text { A SGB is a representation of an indivisible, basic activity of a SG. These } \\
\text { SGBs can be arranged to describe gameplay and learning. (RQ5, 8) }\end{array}$ \\
\hline logic & $\begin{array}{l}\text { Describes how the parameter and/or input of a SGB are processed and } \\
\text { describes the function of a SGB. }\end{array}$ \\
\hline input & $\begin{array}{l}\text { Input defines values obtained from other SGBs which can be processed. } \\
\text { They are used as connection points for information flow connectors. }\end{array}$ \\
\hline output & $\begin{array}{l}\text { If data is processes the output must be specified to pass the data to other } \\
\text { SGBs. They are used as connection points for information connectors. }\end{array}$ \\
\hline
\end{tabular}




\begin{tabular}{|l|l|}
\hline parameter & $\begin{array}{l}\text { Parameters are interchangeable values to adapt the logic (i.e. answers of } \\
\text { assessments). Parameters can be defined when deployed in an SG or } \\
\text { changed through the input of prior SGBs. (RQ2, 4) }\end{array}$ \\
\hline usage description & $\begin{array}{l}\text { Usage description specifies rules for deploying SGBs. These are de- } \\
\text { signed to support the developer to add learning / game content to SGBs } \\
\text { by focusing on the attainment of the educational objective. (RQ2, 4) }\end{array}$ \\
\hline optional & $\begin{array}{l}\text { Defines whether a SGB is optional within a SGP or SGC, and thus could } \\
\text { be omitted during deployment. (RQ7) }\end{array}$ \\
\hline Precondition & $\begin{array}{l}\text { Preconditions are capabilities of a SG which need to be fulfilled before a } \\
\text { SGB can be deployed in a SG. (RQ3) }\end{array}$ \\
\hline Role & $\begin{array}{l}\text { Roles define users who have to fulfill the activities of a SGB, i.e. learn- } \\
\text { er, evaluator or teacher. (RQ16) }\end{array}$ \\
\hline Type & $\begin{array}{l}\text { The type defines the purpose of a SGB or SGC. Type can be presenta- } \\
\text { tion, assessment, feedback or operator. (RQ12-14) }\end{array}$ \\
\hline $\begin{array}{l}\text { Serious Game } \\
\text { Composite (SGC) }\end{array}$ & $\begin{array}{l}\text { SGCs combine two or more SGBs or SGCs "to encapsulate several } \\
\text { indivisible functions to one reusable complex function” [5]. (RQ9) }\end{array}$ \\
\hline General attributes for classes \\
\hline name & Name of the class. \\
\hline description & Description of the class. \\
\hline
\end{tabular}

Initial and final nodes are used to describe the start and end of a composition of activities within a SGP or SGC. Decision/merge and fork/join nodes are used to illustrate excluding and parallel activities (RQ15, 18). Finally, the language consists of two types of connectors [5]. The first kind of connectors is used to describe the logical order of activities (control flow connector) (RQ6). This allows the composition of SGBs to map educational methods to SGs. The second kind of connectors is used to handle the information flow between elements (information flow connectors), i.e. to pass results of an assessment to a feedback to allow adaption (RQ15). The elements of the modeling language are instantiated and combined to describe a SG dynamic, similarly to UML activity diagrams.

\section{$4 \quad$ Conclusion and Outlook}

This paper develops a description of learning processes by specifying and assembling activities linked to pedagogical objectives. The processes can be used during the development of SGs to attain educational objectives within the game. These should be able to fulfill all of the following: (1) describe processes to achieve educational objectives, (2) within SGs, and (3) are reusable and can be deployed repeatedly in various SGs. Based on literature as well as on observation of current practices, we raised requirements for learning processes. Based on these requirements we defined elements and developed a model for a modeling language to describe learning processes. The proposed processes can aid developers to implement educational objectives in a standardized way and, as a result, save time and money during development of SGs.

Our work shows the effect of principles between education and games and particularly, how learning objectives can be integrated as elements in games. Requirements 
and functional specifications are derived from the domain of technology enhanced learning. This paper also raises several issues. It must be examined, if the description of serious game patterns is sufficient to guide the game developers during development. The ease for reuse must be considered and evaluated through practical tests, to determine if the usage descriptions are sufficient. Further research is also needed to evaluate the use of patterns in various SGs.

This research was partially funded by the German Federal Ministry of Education and Research in the project ProduSE (www.projekt-produse.de), FKZ01FL10044.

\section{References}

1. Prensky, M.: Digital Game-Based Learning. McGraw-Hill, New York (2001).

2. Michael, D., Chen, S.: Serious games: Games that educate, train, and inform. Thomson Course Technology PTR (2005).

3. Greitzer, F.L., Kuchar, O.A., Huston, K.: Cognitive science implications for enhancing training effectiveness in a serious gaming context. Journal on Educational Resources in Computing. 7, 10 (2007).

4. Harteveld, C., Guimarães, R.: Balancing pedagogy, game and reality components within a unique serious game for training levee inspection. Technologies for E-Learning and Digital Entertainment. pp. 128-139. Springer Berlin Heidelberg (2007).

5. Hirdes, E.M., Thillainathan, N., Leimeister, J.M.: Modeling Educational Objectives for Serious Games. Pedagogically Driven Serious Games Workshop 2012 (2012).

6. Koper, R., Manderveld, J.: Educational modelling language: modelling reusable, interoperable, rich and personalised units of learning. British Journal of Educational Technology. 35, 537-551 (2004).

7. Janssen, J., Berlanga, A., Vogten, H., Koper, R.: Towards a learning path specification. International journal of continuing engineering education and life long learning. 18, 77-97 (2008).

8. Rawlings, A., Rosmalen, P. van, Koper, R., Rodríguez-Artacho, M., Lefrere, P.: Survey of Educational Modelling Languages (EMLs). (2002).

9. Marchiori, E.J., Del Blanco, Á., Torrente, J., Martinez-Ortiz, I., Fernández-Manjón, B.: A visual language for the creation of narrative educational games. Journal of Visual Languages \& Computing. 22, 443-452 (2011).

10. De Freitas, S., Jarvis, S.: A Framework for developing serious games to meet learner needs. The Interservice/Industry Training, Simulation \& Education Conference. NTSA (2006).

11. Tang, S., Hanneghan, M., El-Rhalibi, A.: Pedagogy Elements, Components and Structures for Serious Games Authoring Environment. 5th International Game Design and Technology Workshop. , Liverpool, UK (2007).

12. Gagné, R.M.: The Conditions of Learning and Theory of Instruction. CBS College Publishing, New York (1985).

13. Schell, J.: The Art of Game Design: A book of lenses. (2008).

14. Garris, R., Ahlers, R., Driskell, J.E.: Games, Motivation, and Learning: A Research and Practice Model. Simulation \& Gaming. 33, 441-467 (2002).

15. Krathwohl, D.R.: A revision of Bloom's taxonomy: An overview. Theory into practice. 41, 212-218 (2002). 